\title{
Agenesis of Maxillary Lateral Incisors: A Multidisciplinary Treatment Approach
}

\author{
Wiem Ben Amor Jemmal ${ }^{1}$, Faten Khanfir ${ }^{1}$, Sofiène Ben Abdallah ${ }^{1}$, Carole Charavet ${ }^{2}$, Adel Ben Amor ${ }^{1}$ and Faten \\ Ben Abdallah Ben Amor ${ }^{1}$
}

${ }^{1}$ Research Laboratory of Oral Health and Rehabilitation (LR12ES11), Faculty of Dental Medicine, Monastir University, Tunisia

${ }^{2}$ Department of Orthodontics and Dentofacial Orthopaedics, University Hospital of Liège, Belgium

Submission: April 01, 2020; Published: May 12, 2020

*Corresponding author: Wiem Ben Amor Jemmali, Research Laboratory of Oral Health and Rehabilitation, Faculty of Dental Medicine, Tunisia

\section{Abstract}

Treatment of maxillary lateral incisor agenesis has always been an area of concern for dental practitioners due to its frequency and the esthetic matter of the anterior sector. Several treatment options have been developed for the replacement of congenitally missing lateral incisors, including canine substitution, single-tooth implants, and tooth-supported restorations. The orthodontist plays a key role in choosing the right treatment option but also in determining and establishing requirements for the treatment plan along with both implantologist and prosthodontist. The aim of this publication was to present a clinical case illustrating the multidisciplinary management of lateral incisor agenesis and to discuss the different treatment approaches with the challenges that we may encounter with each option.

\section{Introduction}

The absence of a lateral incisor may go unnoticed for most individuals whereas the maxillary lateral incisor reveals to be the second most common congenitally absent tooth coming after the second premolars, according to the meta-analysis of Polder et al. [1]. A tooth is defined to be congenitally missing if it has not erupted in the oral cavity and is not visible from radiography and has not been extracted or accidentally lost [2]. Dentists often encounter patients with missing teeth with very low self-esteem.

But, once it is replaced and the smile is improved, it contributes to a total change of one's facial esthetics (Figure 1). According to our previous study among Tunisian population [3], the absence of maxillary lateral incisors was the most common compared to central incisor, canines, premolars, and molars. Therefore, carrying out a case report on this topic contributes to expanding the literature on this topic and to provide relevant information's to dental clinicians including general dentists, pedodontists and orthodontists (Figure 2).

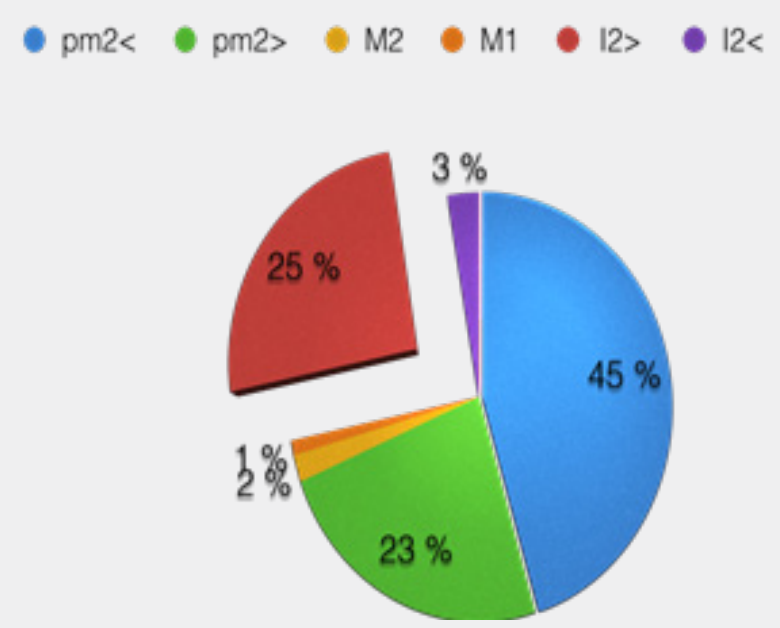

Figure 1: A meta-analysis of the prevalence of dental agenesis of permanent teeth Polder BJ [2] 


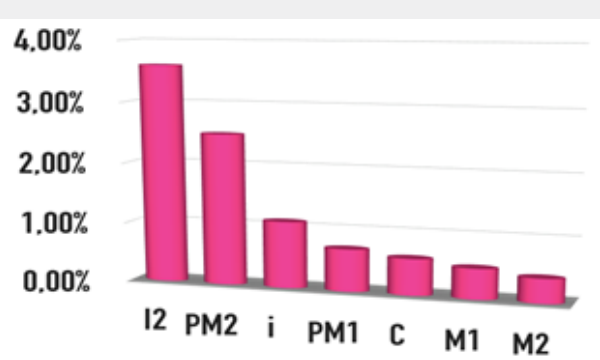

Figure 2: Prevalence of dental agenesis among Tunisian population. University of Monastir (2018).

\section{Diagnosis}

An 18-year old woman came to our department with a chief complaint of an unpleasant smile due to the absence of maxillary lateral incisors. She was healthy and the oral hygiene was excellent. The facial examination showed an asymmetric face, a harmonious profile, and an asymmetric smile (Figure 3).

The intraoral examination revealed several characteristics as follows:

a) Asymmetric upper arch b) Class I Molar and Class II canine

c) Missing 22 and 12

d) Deviation of the upper median line

e) Torsion of 24

f) Distalization of 13 and 23 (Figure 4) 5).

The panoramic X-Ray confirmed agenesis of 12 and 22 (Figure
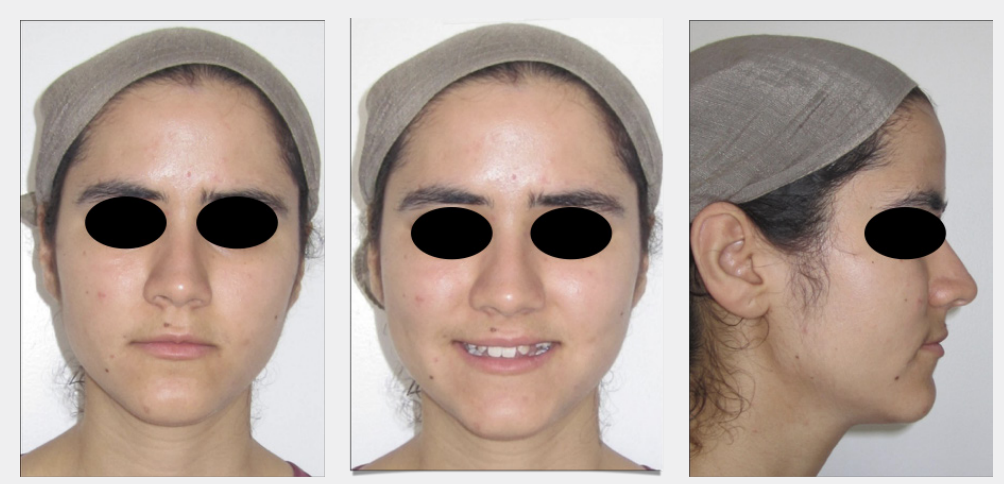

Figure 3: Intraoral examination revealed: Assymetric upper arch, Molar $\mathrm{cl} \mathrm{I} \mathrm{and} \mathrm{canine} \mathrm{cl} \mathrm{II,} \mathrm{Missing} 22$,12.
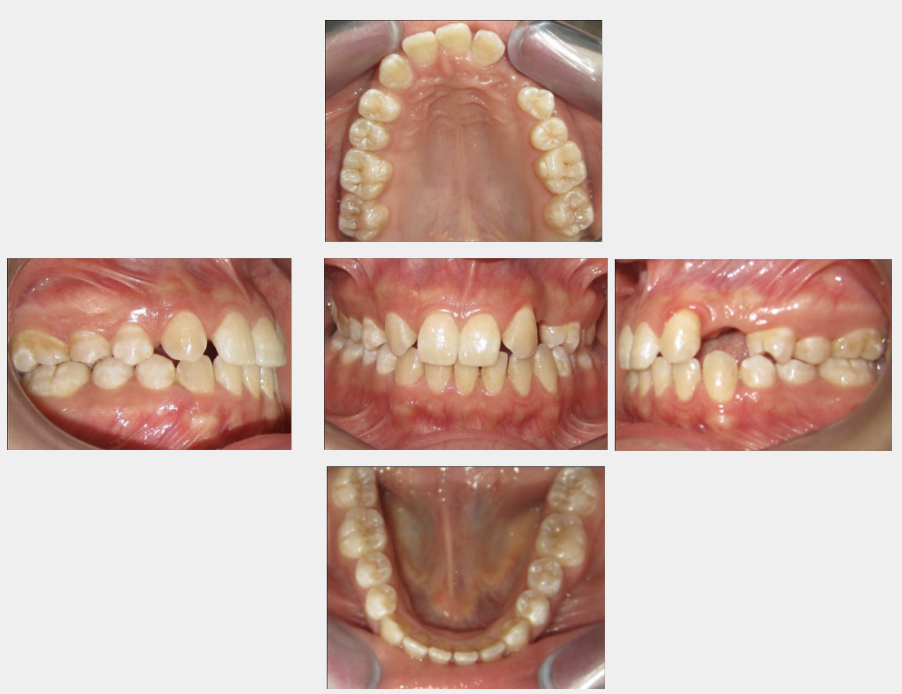

Figure 4: Radiological assessment confirmed agenesis of 12 and 22. 

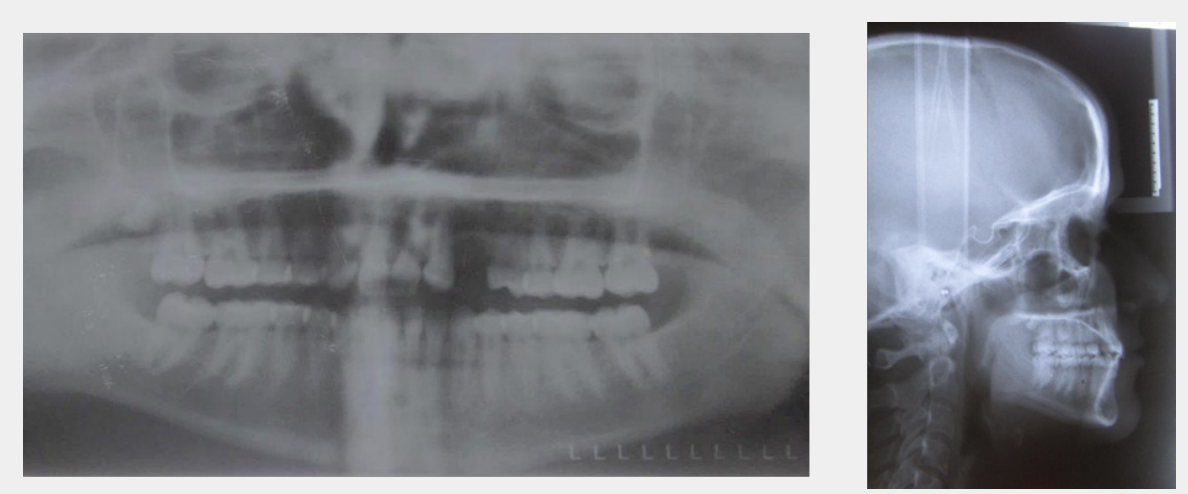

Figure 5: Orthodontic Roth treatment with no extractions, space opening and obtaining canine cl I.

\section{Treatment Objectives}

i. Replacement of lateral incisors (chief complaint)

ii. Harmonization of overjet and overbite

iii. Obtaining both molar and canine Classe I

iv. Improvement of the profile

\section{Orthodontic Procedure}

Roth systems were used. Metal brackets were used for all teeth. The bonding method direct bonding, according to the manufacturer's recommendations. The arch sequence was as follows: $0.014 \mathrm{NiTi}, 0.016 \mathrm{NiTi}, 0.018 \mathrm{NiTi}$ and $0.018 \mathrm{SS}$ for the fine-tuning phase. The strategy to perform space opening for 12 and 22 was to distalize canines on $0.018^{*} 0.025$ SS and then use opening loop right and closing loop left to symmetrize the spaces. The alignement of upper premolars was achieved by a rotational couple of forces and at the end a full class I molar and canine were obtained (Figures 6 \& 7).

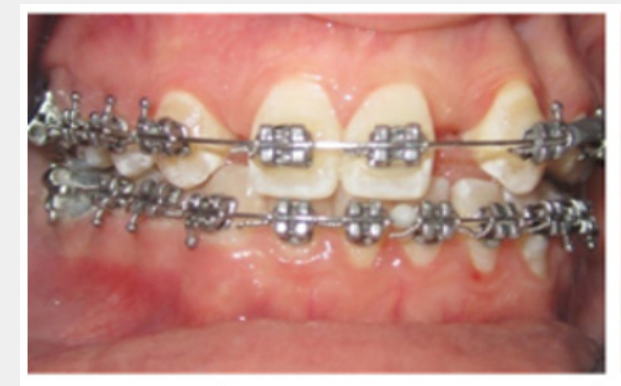

Distalization of the canines $0.018^{*} 0.025 \mathrm{SS}$

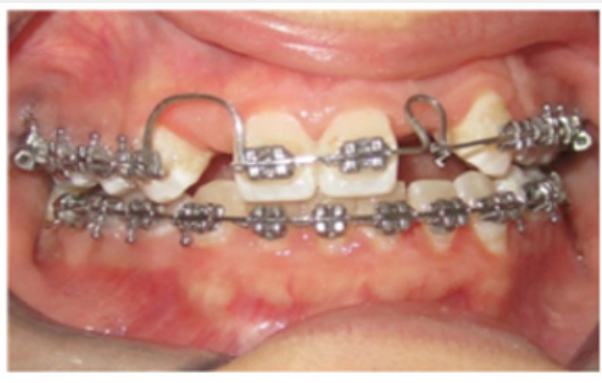

symmetrizing spaces with an opening loop right and closing loop left

Figure 6: Distalization of the canines $0.018^{\star} 0.025 \mathrm{SS}$, Symmetrizing spaces with an opening loop right and closing loop left.

\section{Surgical Procedure}

After the achievement of the space for 12 et 22 , the placement of 2 implants was performed in sites of lateral incisors (Figures 8-13).

\section{Prosthodontic Procedure}

The replacement of 12-22 with implant supported teeth was performed (Figures 14-17).

\section{Discussion}

Globally, three treatment options exist to deal with maxillary lateral agenesis such as space opening, space closure or no treatment. Selecting the appropriate option depends on various criteria [4] as explained below.

\section{Therapeutic Abstention}

This solution is restricted to some indications:

a) No aesthetic complaint from the patient.

b) Small regular spacing.

c) Remaining primary lateral incisor in good condition with permanent canine in the right position.

This solution is generally temporary and regular follow-ups are necessary $[5,6]$. This solution was not retained, according to the chief complaint of the patient. 

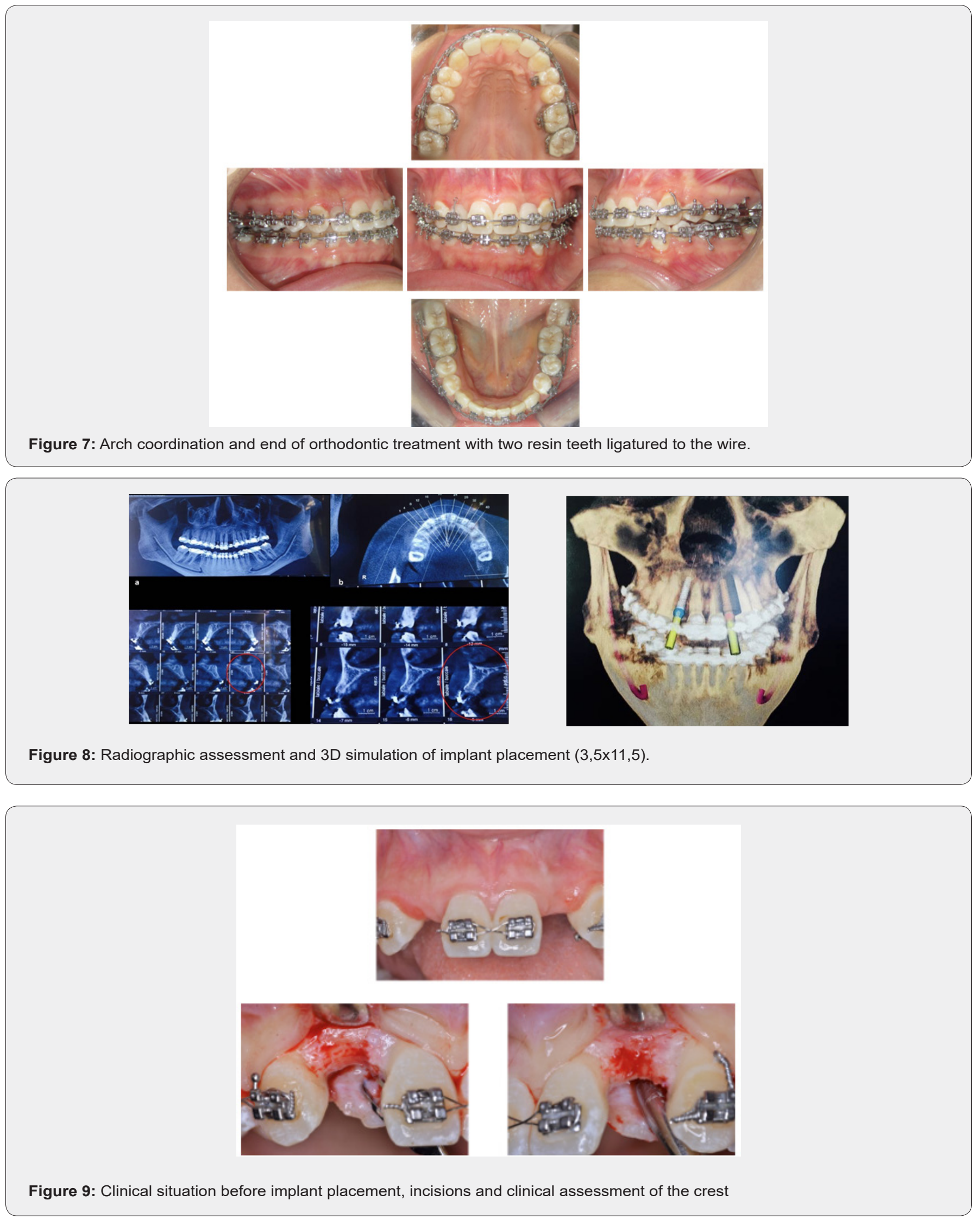


\section{Advances in Dentistry \& Oral Health}
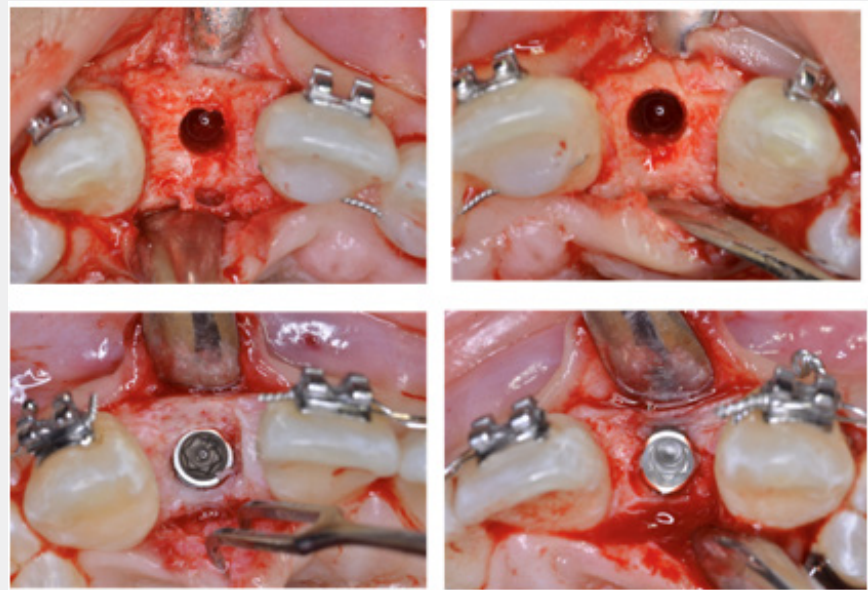

Figure 10: Implant Placement.
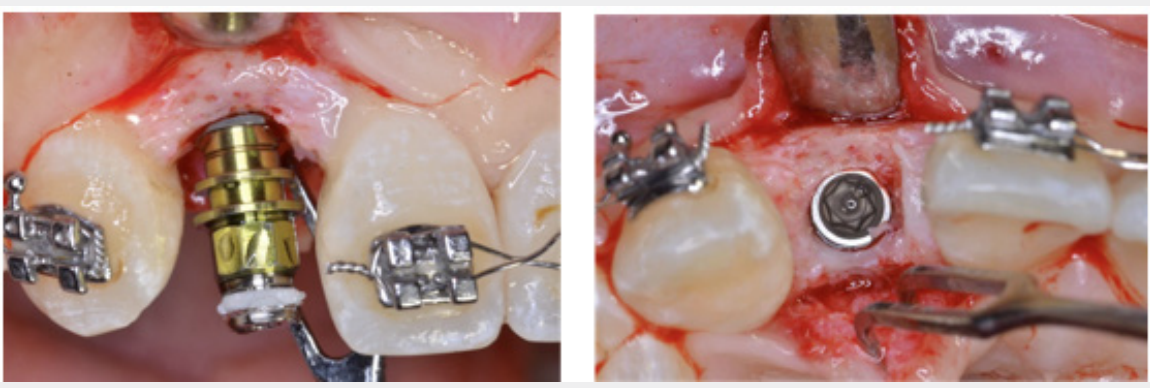

Figure 11: Implant Placement.
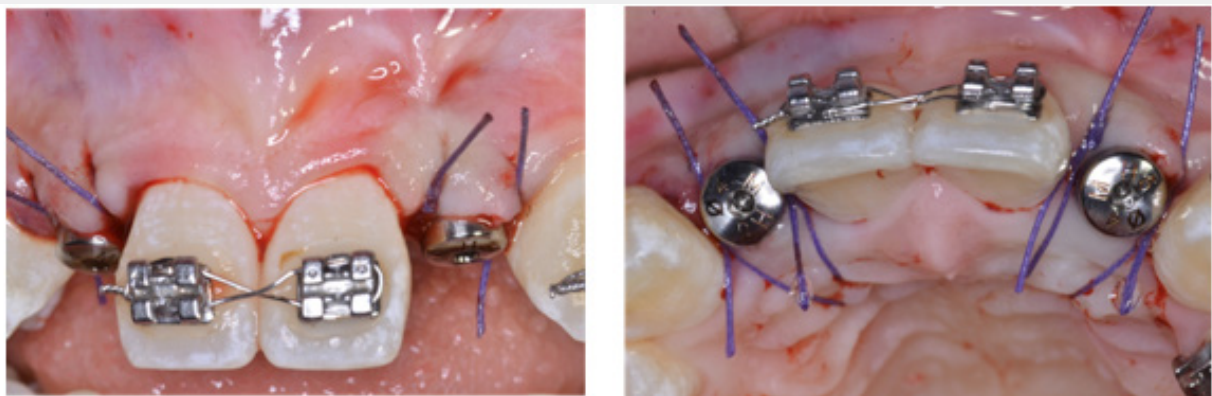

Figure 12: Healing abutment and sutures.

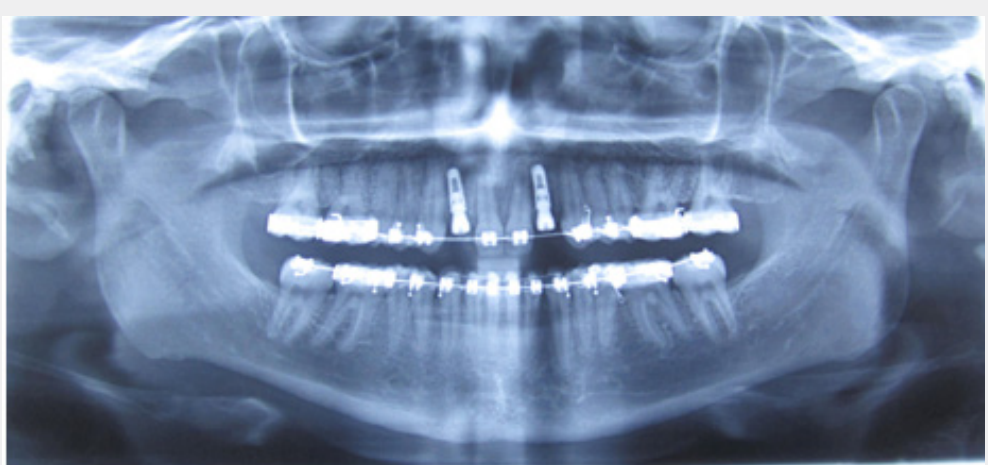

Figure 13: Post-surgical $X$ Ray control. 


\section{Advances in Dentistry \& Oral Health}

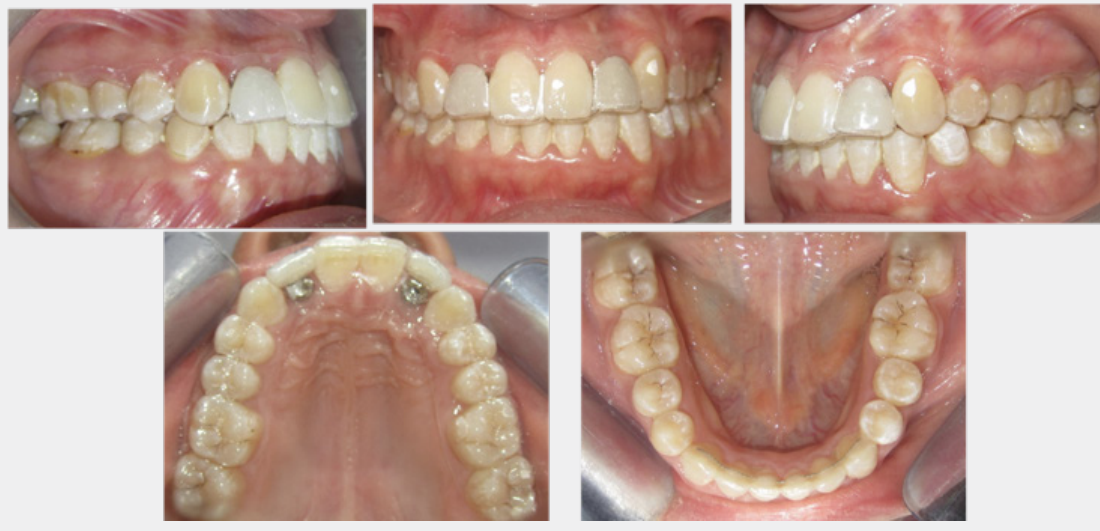

Figure 14: Removal of orthodontic appliance and placement of a bonded retention in the lower arch and Essix retainer with resin interim tooth in it.
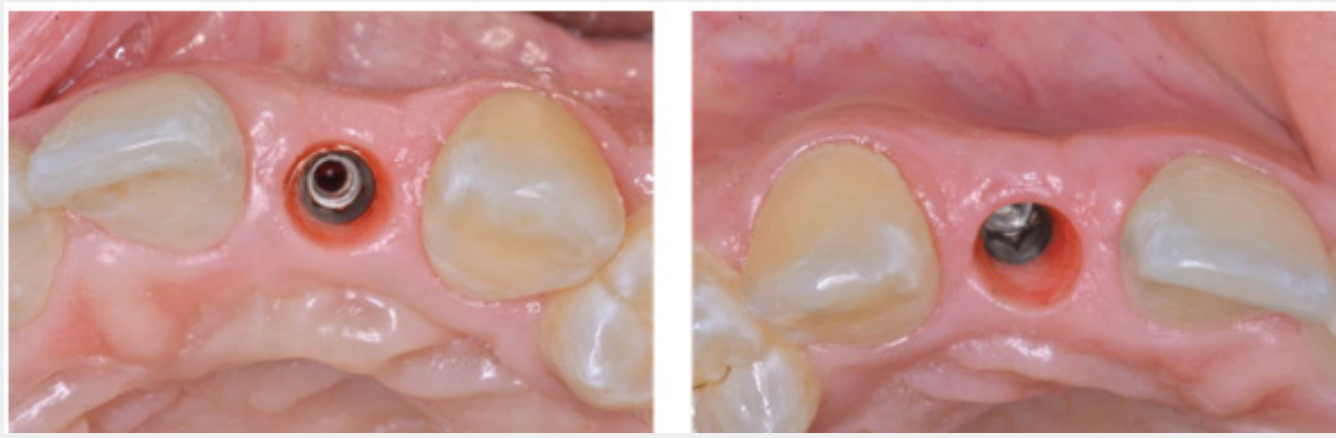

Figure 15: 6 months healing control.
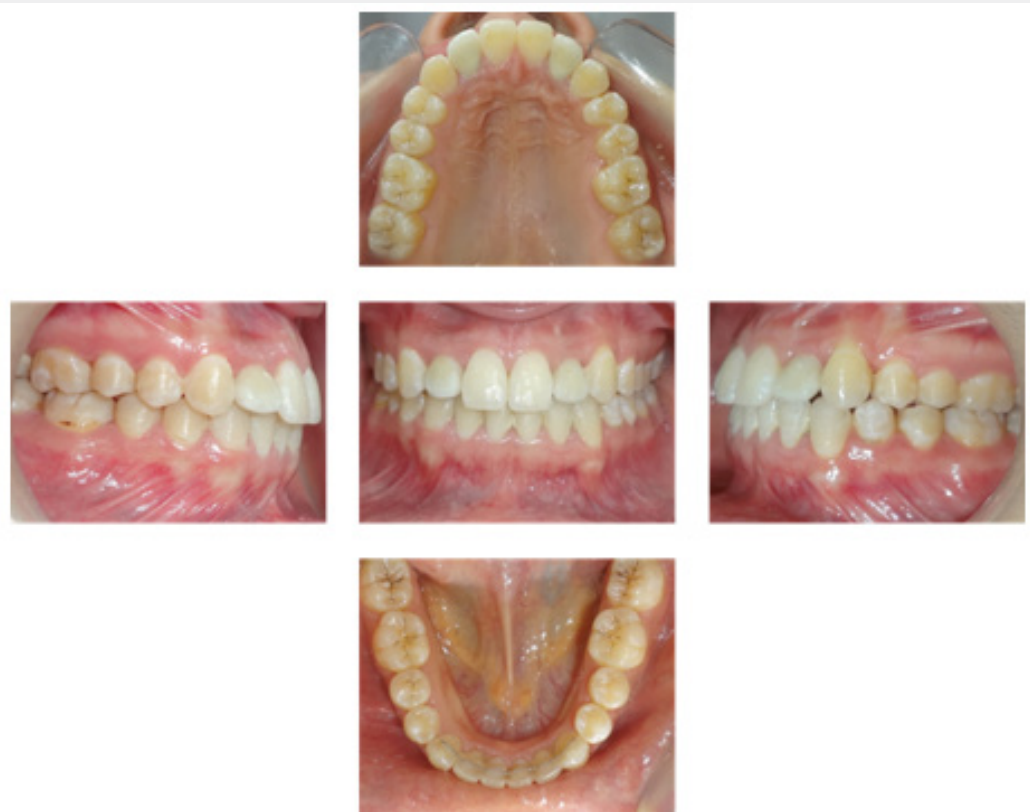

Figure 16: Final result after crown placement. 


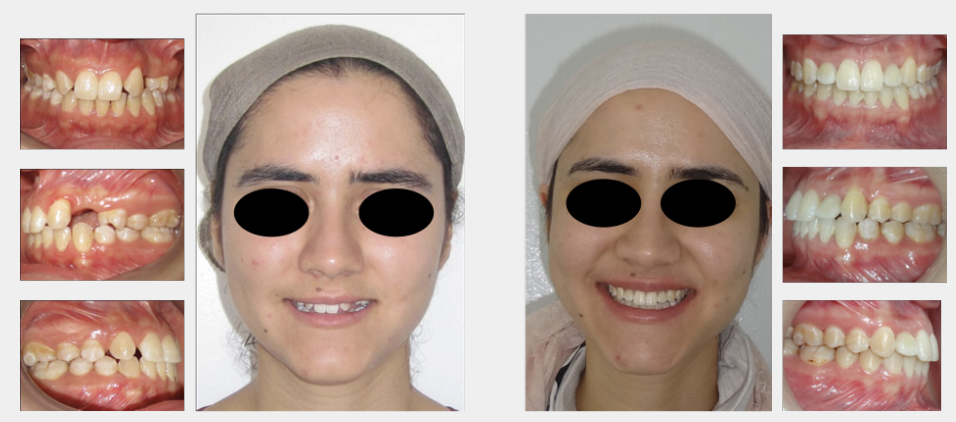

Figure 17: Before and after treatment intraoral and extraoral photographs.

\section{Space Closure}

This option consists in closing the space by positioning the canines to function in place of the missing lateral incisors and then contouring the canines to resemble lateral incisors. We will discuss the following options by listing the challenges it may present and suggesting solutions from the literature to each challenge [7].

The tendency of space reopens after the end of treatment (specially for young patients): This tendency can be overcoming with long-term fixed retention (lingual retainer), proper restorations of the central incisors and first premolars as well as a well-balanced functional occlusion [8].

Problem in matching size, shape, and color: Further improvements by orthodontists in tooth reshaping and progress in restorative treatment with individual tooth bleaching, and thin porcelain veneers demonstrate that quality treatment can be obtained when it is combined with esthetic dentistry. Such results can be almost indistinguishable from natural dentitions [7]. Therefore, this solution of space closure was not retained in our present case report because of the flat profile of the patient and lack of lip support.

\section{Space Opening}

For patients who do not meet the specific qualifications necessary to be considered optimal candidates for canine substitution, Restorative treatment alternatives must be considered. Restorative treatment alternatives can be a singletooth implant, a resin bonded Fixed Partial Denture (FPD) or a conventional full-coverage FPD [9]. The primary consideration, when deciding which option to choose, is conservation of tooth structure. Nowadays, the single-tooth implant has become the most popular treatment alternative for the replacement of missing teeth. In addition to the high success rates, one main benefit of this type of restoration is that it leaves the adjacent teeth untouched [10]. This is particularly important in young patients and unrestored dentitions. However, the main problems encountered while choosing that option are:

Timing of implant placement: The appropriate time to place an implant is based on a patient's facial growth [11]. If an implant is placed before the completion of the facial growth of the patient, significant periodontal, occlusal, and esthetic problems can be created, especially infraculusion [12]. To avoid this major adverse event, we should check that face growth has finished before placing any implant, as is the case in our patient. The most predictable way to monitor facial growth is by evaluating serial cephalometric radiographs taken 6 months to 1 year apart. If 2 sequential radiographs show no growth, then an implant can be placed [9].

Interim tooth replacement after orthodontics: As implants cannot be placed until facial growth is complete, an interim tooth could be placed in order to restore function and aesthetic and maintain the edentulous space [9]. Otherwise, it is possible to see the space close making future implant placement impossible. This interim tooth can be a removable retainer with a prosthetic tooth (short term solution), a Resin bonded FPD, or a removable partial denture.

Insufficient interradicular spacing: Inadequate space between the root apices is generally due to improper root angulation which is enhanced by the use of spring coils during space opening [13]. Therefore, it is important to perform periapical radiographs of the edentulous area before removing the orthodontic appliances. It is advised to angulate the position of central and canine brackets in a way that leads to root separation at an early stage of the treatment [14].

Inadequate Implant site: Without the development and eruption of the permanent lateral incisor, the osseous ridge in this area is typically deficient. Added to that, according to a study conducted by Bertl in 2016, an increased mesio-distal gap width correlate significantly with reduced edentulous ridge thikness. A mesiodistal gap of $>6 \mathrm{~mm}$ was associated with thin bucco-palatal alveolar ridges, precluding straightforward implant placement in $60-80 \%$ of the cases [15].

Therefore, to prevent this major issue, permanent canine should be induced to erupt mesially through the alveolus, its large buccolingual width will influence the thickness of the edentulous ridge. Then, after the permanent canine is orthodontically moved distally, an increased buccolingual alveolar width is established 
[16]. In 2015, Birt Melsen suggested the insertion of transcortical screws in order to contribute to the maintenance of both quantity and quality of the alveolar process thereby reducing the need for reconstruction surgery before the insertion of implants [17]. Moreover, this same mini screw is used to retain an interim pontic in growing patients or when a permanent restorative solution has to be postponed for any other reason. If those measures are not taken precociously, bone thickness is augmented by using a proper surgical technique, such as guided bone regeneration with barrier membranes and appropriate bone grafts and bone substitutes. According to the discussion above, in our present clinical case, the solution of space opening was chosen because of the high esthetic expectation of the patient, considering the adequate implant site and her young age.

\section{Conclusion}

i. An interdisciplinary diagnostic and treatment perspective must be performed to manage agenesis cases. By creating that team approach. The orthodontist, restorative dentist, surgeon, and prosthodontist team can produce predictable and esthetic treatment results.

\section{References}

1. Polder, Bart J, Van't Hof, Martin A, Van Der Linden, et al. (2004) A meta-analysis of the prevalence of dental agenesis of permanent teeth. Community dentistry and oral epidemiology 32(3): 217-226.

2. Textbook of Oral and Maxillofacial pathology by S Neville, Damn Allen, Bouquot $3^{\text {rd }}$ edition. Elsevier Publications, a division of Reed Elsevier India Pvt ltd. JSER p. 77-80.

3. Dallel, Inès, Marwen, Wiem, Abdallah, et al. (2018) L'agénésie des incisives latérales supérieures: étude d'une population orthodontique et illustration clinique. International Orthodontics 16(2): 384-407.

4. Andrade DCM, Loureiro CA, Araújo VE (2013) Treatment for agenesis of maxillary lateral incisors: a systematic review. Orthodontics \& craniofacial research 16(3): 129-136.

5. Boujoual, Imane, EL Yamani, Amal, Andoh, et al. (2018) Conduite à tenir face à l'absence d'une incisive latérale supérieure Managing the absence of the maxillary lateral incisor.
6. Abu-Hussein, Muhamad (2016) Congenitally Missing Lateral Incisors; Orthodontic, Restorative, and Implant Approaches. Int J Dent 2(2).

7. Rosa, Marco, Zachrisson, Björn U (2010) The space-closure alternative for missing maxillary lateral incisors: an update. Journal of clinical orthodontics: JCO 44(9): 540-549.

8. Savarrio, Lee, Mcintyre, Grant T (2005) To open or to close space-that is the missing lateral incisor question. Dental Update 32(1): 16-25.

9. Kokich, Vincent O, Kinzer, Greggory A, Janakievski, et al. (2011) Congenitally missing maxillary lateral incisors: restorative replacement. American Journal of Orthodontics and Dentofacial Orthopedics 139(4): 443.

10. AL-Quran, Firas A, AL-Ghalayini, Raed F, AL-ZU'BI, et al. (2011) Singletooth replacement: factors affecting different prosthetic treatment modalities. BMC oral health 11(1): 34 .

11. Shah, Rohit A, Mitra, Dipika K, Rodrigues, et al. (2013) Implants in adolescents. Journal of Indian Society of Periodontology 17(4): 546548.

12. Agarwal, Nidhi, Kumar, Dipanshu, Anand, et al. (2016) Dental implants in children: A multidisciplinary perspective for long-term success. National journal of maxillofacial surgery 7(2): 122-126.

13. Shastri, Dipti, Tandon, Pradeep, Gyan P, et al. (2014) A newer simultaneous space creation, eruption, and adjacent root control spring for the management of impacted tooth. Contemporary clinical dentistry 5(4): 555-557.

14. Kokich, Vincent G (2004) Maxillary lateral incisor implants: planning with the aid of orthodontics. Journal of oral and maxillofacial surgery 62: 48-56.

15. Bertl, Kristina, Grotthoff, Verena Schulze, Bertl, et al. (2017) A wide mesio-distal gap in sites of congenitally missing maxillary lateral incisors is related to a thin alveolar ridge. Clinical oral implants research 28(9): 1038-1045.

16. Nováčková, Soňa, Marek, Ivo, Kamínek, et al. (2011) Orthodontic tooth movement: bone formation and its stability over time. American journal of orthodontics and dentofacial orthopedics 139(1): 37-43.

17. Melsen, Birte, Huja SS, Chien HH, (2015) Alveolar bone preservation subsequent to miniscrew implant placement in a canine model. Orthodontics \& craniofacial research 18(2): 77-85.

\begin{tabular}{l} 
Your next submission with Juniper Publishers \\
will reach you the below assets \\
- Quality Editorial service \\
- Swift Peer Review \\
- Reprints availability \\
- E-prints Service \\
- Manuscript Podcast for convenient understanding \\
- Global attainment for your research \\
- Manuscript accessibility in different formats \\
( Pdf, E-pub, Full Text, Audio) \\
- Unceasing customer service \\
Track the below URL for one-step submission \\
https://juniperpublishers.com/online-submission.php \\
\hline
\end{tabular}

